\title{
ELISITASI KEBUTUHAN PERANGKAT LUNAK REKRUTMEN PEGAWAI DENGAN PENDEKATAN SOFT SYSTEM METHODOLOGY

\author{
Danuri $^{1}$, dan Jaroji ${ }^{2}$
}

1,2 Program Studi Rekayasa Perangkat Lunak, Jurusan Teknik Informatika, Politeknik Negeri Bengkalis, Jl.Bathin Alam - Sungai Alam, Bengkalis - Riau, 28711 e-mail: ${ }^{1}$ danuri@polbeng.ac.id, ${ }^{2 j}$ jaroji@polbeng.ac.id

\begin{abstract}
Abstrak - Pembangunan Perangkat Lunak diawali proses analisa terhadap kebutuhan perangkat lunak dari pengguna. Masalah yang dihadapi adalah keterbatasan dalam menyampaikan informasi mengenai sistem rekrutmen pegawai yang bersifat konvensional dan belum terstruktur dengan baik. Soft System Methodology digunakan sebagai pendekatan untuk mengindentifikasi masalah yang akan diselesaikan secara menyeluruh melalui 7 tahapan. Teknik Rich Picture digunakan untuk mendapatkan gambaran yang luas dari sejumlah masalah yang muncul. Proses analisis logik terhadap pemodelan masalah pada tahap root defenition memanfaatkan model CATWOE. Hasil yang diperoleh berupa pemetaan permasalahan dan kebutuhan pengguna yang terstruktur.
\end{abstract}

Kata Kunci: Soft System Methodology, Rich Picture, CATWOE, Rekrutmen Pegawai

\section{PENDAhuluan}

Sumber daya manusia dalam sebuah institusi merupakan aset berharga yang harus terus dijaga kuantitas dan kualitasnya agar sesuai dengan kebutuhan institusi. Proses ini melibatkan banyak proses, salah satunya adalah proses rekrutment pegawai yang berkualitas. Rekrutmen sebagai suatu proses pengumpulan calon pemegang jabatan yang sesuai dengan pegawai untuk menduduki suatu jabatan tertentu dalam fungsi pekerjaan (employee function) pegawai (Yulyanti, 2009). Politeknik Negeri Bengkalis (Polbeng) merupakan institusi perguruan tinggi vokasi berada di bawah Kementrian Riset Teknologi dan Pendidikan Tinggi. Pegawai yang bekerja di Polbeng terdiri Pegawai Negeri Sipil (PNS), pegawai tetap non PNS dan pegawai tidak tetap. Proses rekrutmen pegawai terdiri dari dua, yaitu rekrutmen PNS dan pegawai tidak tetap. Rekrutmen yang dilaksanakan secara mandiri oleh Polbeng adalah rekrutmen pegawai tidak tetap, proses rekrutmen ini dilakukan untuk mengisi kekosongan formasi baik untuk dosen maupun tenaga kependidikan.

Proses rekrutmen pegawai yang dilakukan secara mandiri oleh Polbeng masih menggunakan cara manual. Proses-proses manual tersebut selain lama dan tidak efisien namun juga menimbulkan beragam persepsi dari berbagai user, misalnya calon pelamar yang tidak dipanggil untuk ikut $\mathrm{TKD}$, merasa bahwa proses rekrutmen kurang transparan karena tidak mendapatkan informasi mengapa yang bersangkutan tidak dipanggil. Begitu juga calon pegawai yang tidak di panggil untuk mengkuti TKB, mereka tidak mendapatkan hasil TKD yang diikuti. Persepsi-persepsi lain juga muncul dari kalangan internal bahwa sistem rekrutmen masih manual, menyulitkan dan kurang transparan. Berdasarkan permasalahanpermasalahan tersebut, ingin dibangun perangkat lunak untuk rekurtmen pegawai. Upaya untuk mendapatkan kebutuhan perangkat lunak yang sesuai dengan kebutuhan sistem rekrutmen pegawai Polbeng, dilakukan elisitasi kebutuhan menggunakan pendekatan Soft System Methodology.

\section{METODE PENELITIAN \\ 2.1 Elisitasi Kebutuhan}

Sommervile dan Sawyer dalam [5] mendefinisikan elisitasi kebutuhan sebagai sekumpulan aktivitas yang ditujukan untuk menemukan kebutuhan suatu sistem melalui komunikasi dengan pelanggan, pengguna sistem dan pihak lain yang memiliki kepentingan dalam pengembangan sistem.

Terdapat beberapa teknik dalam elisitasi kebutuhan yaitu [2]:

1. Wawancara

2. Workshop

3. Survey pasar

4. Pemeriksaan problem reports

5. Observasi

6. Etnografi

Pada penelitian ini diambil teknik wawancara dan observasi pada sistem rekurtmen pegawai di Polbeng.

\subsection{Soft System Methodology (SSM)}

Soft System Methodology (SSM) adalah suatu metode yang digunakan dimana merupakan proses yang melibatkan lingkungan dengan hubungan relevan antara yang nyata dan sistem (model konseptual), dengan harapan dapat menemukan dan mendefinisikan masalah yang memberikan alternatif perubahan [3].

Ide dasar dari pemikiran soft system ialah konsep sistem digunakan sebagai cara untuk menyelidiki ke dalam dunia yang dipersepsikan. Ide-ide sistem berdasarkan konsep ' $a$ whole' dimana suatu organisasi dapat dilihat sebagai suatu keseluruhan yang utuh dimana keseluruhan 
(the whole) lebih berarti daripada jumlah bagianbagiannya [1].

SSM tidak membatasi permasalahan pada variabel tertentu saja namun mencoba mengindentifikasikan sebanyak mungkin aspek (variabel) yang berinteraksi di dalam sistem. Dengan demikian pendefinisian permasalahan akan lebih lengkap karena mempertimbangkan banyak aspek dan mampu mengantisipasi kemungkinan perubahan (dinamika) yang akan terjadi (Nugroho, 2012).

Checkland dalam [1] mendefinisikan 7 tahap dalam SSM yang dikenal juga dengan nama Checkland protocol seperti yang tergambar dalam bagan berikut ini:

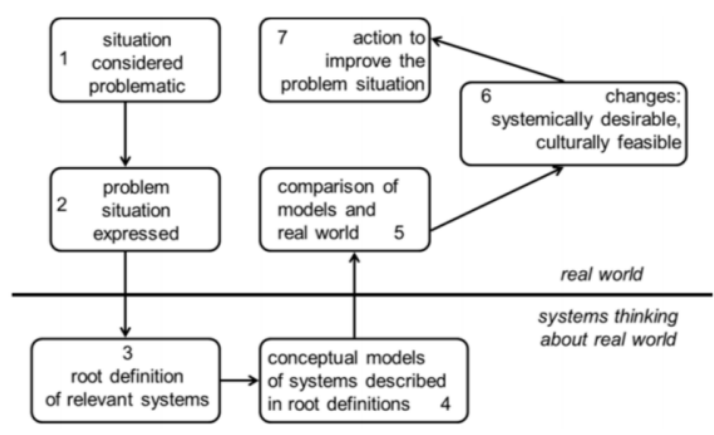

Gambar 1. Checkland Protocol

1. Situasi permasalahan (problem situation), yaitu mulai mengenali situasi dan permasalahan yang sedang terjadi pada domain yang sedang diobservasi.

2. Penggambaran situasi permasalahan kedalam diagram rich picture (problem situation expressed), yaitu menggambar sketsa situasi real permasalahan kedalam sebuah diagram rich picture yang besar (helicopter view).

3. Pendefinisian kata-kata kunci (root definitions), yaitu mulai mengumpulkan kata-kata kunci yang harus didefinisikan masing-masing ke dalam bentuk jalan cerita proses bisnis secara tektual dan ringkas. Dari Root Definition ini dipetakan ke dalam elemen CATWOE (Client, Actor, Transformation, World view, owner, environment).

4. Pembuatan model sistem berdasarkan root definitions (conceptual modeling), untuk setiap definisi dibuatkan sebuah diagram model dalam bentuk diagram rich picture.

5. Membandingkan model dengan situasi sesungguhnya (comparison of models and real world), yaitu melakukan perbandingan antara sketsa situasi riil dengan model yang dibuat.

6. Melakukan perubahan/penyesuaian (changes), jika ada perbedaan maka dilakukan penyesuaian-penyesuaian hingga model konseptual sudah sesuai dengan situasi riil.

7. Melakukan perbaikan/solusi untuk sistem yang direkomendasikan (action to improve the problem situation), fase akhir adalah melakukan rekomendasi-rekomendasi perbaikan terhadap sistem yang lama.

\subsection{Tahapan Penelitian}

Berikut ini langkah-langkah yang dilakukan pada saat kegiatan penelitian:

1. Identifikasi permasalahan-permsalahan yang terjadi pada sistem rekrutmen pegawai melalui proses wawancara dan observasi.

2. Analisasi permasalahan menggunakan pendekatan SSM untuk menemukan solusi dan rekomendasi terbaik.

\section{HASIL DAN PEMBAHASAN}

Elisitasi kebutuhan perangkat lunak rekrutmen pegawai di Polbeng dengan pendekatan Soft System Methodology terdiri dari tahapan-tahapan berikut ini:

\subsection{Deskripsi Situasi Permasalahan}

Proses rekrutmen yang dilakukan secara mandiri oleh Polbeng masih menggunakan cara manual, dimulai dengan mengumumkan lowongan pekerjaan melaui media sosial, website dan email. Berkas lamaran pekerjaan dikirim melalui email oleh pelamar ke email yang disediakan oleh Polbeng. Berkas tersebut satu per satu direkap oleh bagian kepegawaian yang relatif lama dan selanjutnya dilakukan seleksi kelengkapan berkas sesuai dengan kriteria/kualifikasi pegawai yang akan diterima. Pelamar yang dinyatakan lolos seleksi administrasi akan dimumukan melalui website Polbeng sekaligus sebagai pemanggilan tes kompetensi dasar (TKD) pada jadwal yang telah ditetapkan. Setelah pelaksanaan TKD, diumumkan calon pegawai yang dinayatakan lulus TKD. Selanjutnya pegawai yang lulus TKD mengikuti Test Kompetensi Bidang (TKB) dan interview. TKB dilakukan pada masing-masing unit kerja sedangkan interview dilakukan oleh pimpinan. Setelah proses tersebut, ditetapkan calon pegawai yang diterima sebagai pegawai tidak tetap Polbeng. Proses-proses tersebut kecuali TKD masih dilakukan secara manual.

Proses-proses manual tersebut selain lama dan tidak efisien namun juga menimbulkan beragam persepsi dari berbagai user, misalnya calon pelamar yang tidak dipanggil untuk ikut TKD, merasa bahwa proses rekrutmen kurang transparan karena tidak mendapatkan informasi mengapa yang bersangkutan tidak dipanggil. Begitu juga calon pegawai yang tidak di panggil 
untuk mengkuti TKB, mereka tidak mendapatkan hasil TKD yang diikuti. Persepsi-persepsi lain juga muncul dari kalangan internal bahwa sistem rekrutmen masih manual, menyulitkan dan kurang transparan.

\subsection{Penggambaran Situasi Permasalahan dengan Rich Picture \\ Penggambaran situasi permasalahan} kedalam diagram rich picture dilakukan untuk memberikan gambaran situasi nyata permasalahan yang terjadi seperti yang terlihat pada gambar $1 \mathrm{di}$ bawah ini.

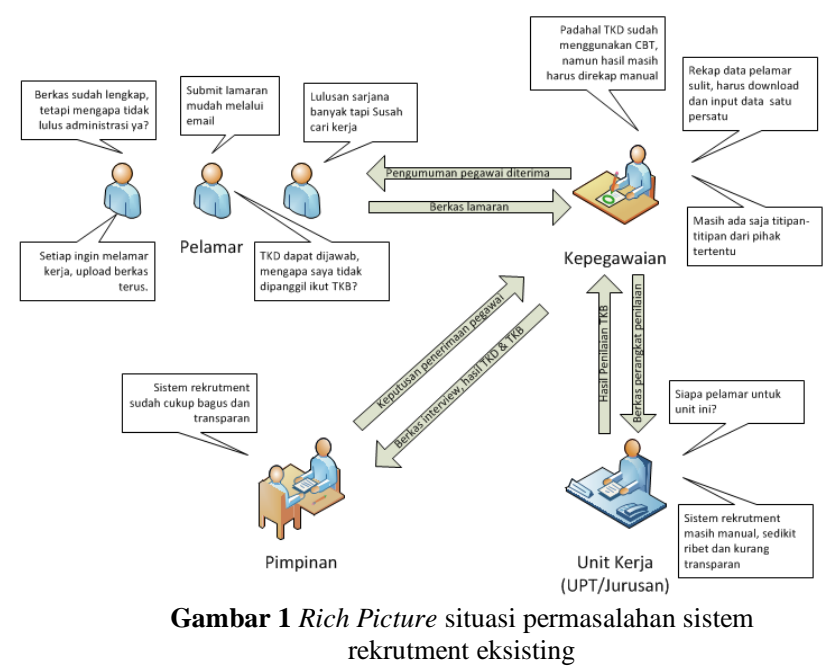

\subsection{Pendefinisian Kata-kata Kunci (Root Definition)}

Bentuk dari 'root definition' adalah: A system to do $\mathrm{X}$, by (means of) $\mathrm{Y}$ in order to do $\mathrm{Z}$ (Nugroho, 2012). Dengan X, Y, Z sebagai berikut:
a. $\mathrm{X}$ : apa yang sistem lakukan
b. Y : bagaimana dikerjakan
c. Z : mengapa dikerjakan

Dari bentuk tersebut maka dirumuskan "root definition" sebagai berikut: Bagian kepegawaian dapat mengusulkan pembuatan perangkat lunak rekrutmen pegawai yang mampu menerima lamaran kerja secara online, sistem rekap pelamar otomatis, integrasi dengan sistem CBT, penilaian TKB online (X). Perangkat lunak tersebut dikerjakan oleh Unit Komputer Jaringan dan Perangkat lunak atau menjadi topik penelitian bagi Dosen, sehingga perangkat lunak tersebut tahun berikutnya dapat digunakan (Y). Perangkat lunak tersebut dikerjakan untuk memudahkan proses rekrutmen pegawai bagi pelamar, bagian kepegawaian dan unit kerja serta meningkatkan transaparasi proses penerimaan pegawai $(\mathrm{Z})$.

Sedangkan dalam analisis elemen CATWOE (Client, Actor, Transformation, World view, Owner, Environment) adalah sebagai berikut :
a. $\mathrm{C}$ : Pelamar dan unit kerja
b. A : Staff kepegawaian
c. $\mathrm{T}$ : Proses sistem rekrutmen pegawai manual menjadi perangkat lunak rekrutmen pegawai online.

d. W : Memudahkan proses rekrutmen pegawai dimulai dari penerimaan berkas, rekapitulasi pelamar, impor nilai TKD dan rekap nilai TKB serta meningkatnya transparasi proses rekrutmen tersebut.

e. $\mathrm{O}$ : Polbeng

f. E : Sistem rekrutmen sesuai SOP penerimaan pegawai yang berlaku di Polbeng.

\subsection{Pembuatan Model Sistem Berdasarkan Root Definitions (Conceptual Modeling)}

Berdasarkan hasil dari analisis masalah yang muncul dari langkah-langkah sebelumnya, maka dirancang model konseptual berupa pembuatan perangkat lunak rekrutmen pegawai online berbasis web dengan memperhatikan ukuran performansi efficacy, efficiency dan effectiveness (Nugroho, 2012). Gambar 2 berikut ini merupakan rich picture untuk menggambarkan copceptual modeling yang dibuat

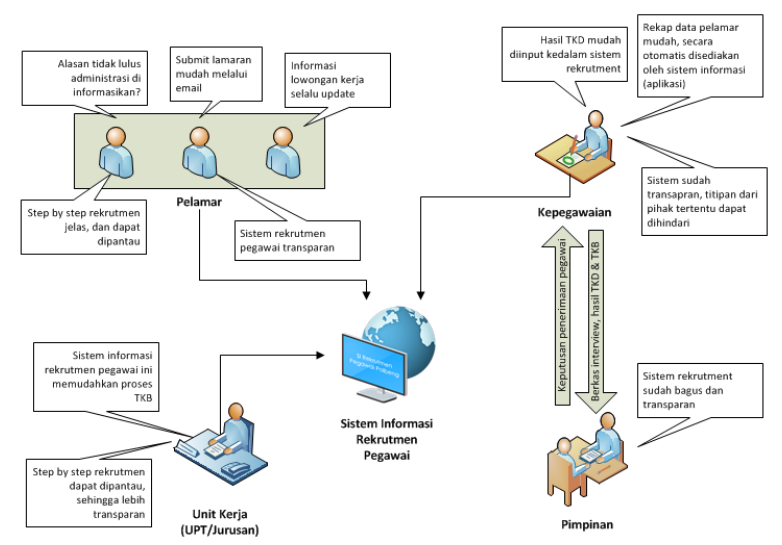

Gambar 2. Rich Picture Conceptual Model

Ukuran performansi:

1. Effacacy: Apakah penggunaan perangkat lunak ini dapat meningkatkan transparansi dalam proses rekrutment pegawai?

2. Efficiency: Apakah penggunaan perangkat lunak ini dapat menghemat waktu dan baiaya dalam proses pengiriman lamaran kerja, rekap data, proses penilaian TKD dan TKB?

3. Effectivness: Apakah penggunaan perangkat lunak ini merupakan solusi yang paling tepat untuk mengatasi permasalahan yang terjadi pada pelamar kerja, staff kepegawaian dan unit kerja?

\subsection{Membandingkan dan Penyesuaian Model Dengan Situasi Sesungguhnya}


Pada tahap ini merupakan step 5 dan 6 dilakukan perbandingan antara conceptual model dengan situasi nyata dan penyesuaian jika terjadi perbedaan. Perbandingan ini dilakukan pada aspek fungsionalitas sistem rekrutmen pegawai dan dukungan teknologi yang dibutuhkan.

Tabel 1 Perbandingan conceptual model dengan situasi ril

\begin{tabular}{|c|c|c|}
\hline Aspek perbandingan & Situasi ril & Penyesuaian \\
\hline \multicolumn{3}{|l|}{ Fungsionalitas sistem } \\
\hline $\begin{array}{l}\text { Proses pengiriman } \\
\text { lamaran kerja }\end{array}$ & $\begin{array}{l}\text { Beberapa pelamar } \\
\text { masih belum } \\
\text { familiar dengan } \\
\text { perangkat lunak } \\
\text { rekrutmen } \\
\text { pegawai }\end{array}$ & $\begin{array}{l}\text { Membuat } \\
\text { user manual } \\
\text { dan } \\
\text { menerima } \\
\text { masukan } \\
\text { dari } \\
\text { pelamar }\end{array}$ \\
\hline $\begin{array}{ll}\text { - } & \text { Proses rekap } \\
\text { lamaran kerja oleh } \\
\text { staff kepegawaian }\end{array}$ & $\begin{array}{l}\text { Sudah berjalan } \\
\text { dengan baik }\end{array}$ & - \\
\hline $\begin{array}{l}\text { Proses rekap nilai } \\
\text { TKD dan TKB } \\
\text { kerja oleh staff } \\
\text { kepegawaian }\end{array}$ & $\begin{array}{l}\text { Sudah berjalan } \\
\text { dengan baik }\end{array}$ & - \\
\hline 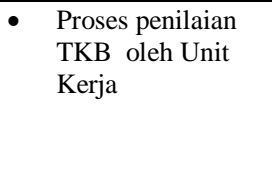 & $\begin{array}{l}\text { Beberapa unit } \\
\text { kerja belum } \\
\text { familiar dengan } \\
\text { perangkat lunak } \\
\text { ini }\end{array}$ & $\begin{array}{l}\text { Membuat } \\
\text { user manual } \\
\text { dan } \\
\text { pelatihan }\end{array}$ \\
\hline $\begin{array}{ll}\text { - Integrasi dengan } \\
\text { sistem CBT }\end{array}$ & $\begin{array}{l}\text { Masih ada } \\
\text { kendala karena } \\
\text { belum secara } \\
\text { otomatis hasil } \\
\text { TKD masuk ke } \\
\text { sistem rekrutmen } \\
\text { pegawai }\end{array}$ & $\begin{array}{l}\text { Melakukan } \\
\text { integrasi } \\
\text { terhadap } \\
\text { sistem CBT }\end{array}$ \\
\hline
\end{tabular}

\subsection{Melakukan Perbaikan/solusi Untuk} Sistem Yang Direkomendasikan

Tabel 2 Rekomendasi perbaikan conceptual model

\begin{tabular}{lll}
\hline \multicolumn{2}{c}{ Penyesuaian } & \multicolumn{1}{c}{ Rekomendasi } \\
\hline & $\begin{array}{l}\text { Membuat user } \\
\text { manual dan survei }\end{array}$ & $\begin{array}{l}\text { Membuat user manual yang } \\
\text { komunikatif dan menyediakan } \\
\text { menu akses user manual yang } \\
\text { mudah terlihat, menyedian } \\
\text { fasilitas penerimaan saran dari } \\
\text { pelamar untuk perbaikan tampilan } \\
\text { perangkat lunak, menyediakan } \\
\text { helpdesk untuk membantu pelamar } \\
\text { yang mengalami kesulitan dalam } \\
\text { menggunakan perangkat lunak } \\
\text { tersebut }\end{array}$ \\
\hline $\begin{array}{l}\text { Membuat user } \\
\text { manual dan } \\
\text { pelatihan }\end{array}$ & $\begin{array}{l}\text { Membuat user manual yang } \\
\text { komunikatif dan melatih unit kerja } \\
\text { agar dapat menggunakan } \\
\text { perangkat lunak tersebut }\end{array}$ \\
\hline $\begin{array}{l}\text { Melakukan } \\
\text { integrasi terhadap } \\
\text { sistem CBT }\end{array}$ & $\begin{array}{l}\text { Mempelajari teknologi CBT yang } \\
\text { digunakan dan membuat web } \\
\text { service di sisi CBT agar perangkat } \\
\text { lunak rekrutmen pegawai dapat } \\
\text { mengakses hasil TKB dengan } \\
\text { aman. }\end{array}$ \\
\hline
\end{tabular}

\section{SIMPULAN}

Simpulan yang dapat diambil dari pembahasan dan hasil yang didapatkan adalah elisitasi perangkat lunak dengan pendekatan Soft System Methodology menunjukan bahwa kebutuhan perangkat lunak sudah terlihat pada step penggambaran situasi permasalahan. Dengan pendekatan ini, pengembang juga dapat berfikir secara system thinking dan dapat melakukan perbaikan terhadap conceptual model sehingga ditemukan model terbaik untuk pembuatan perangkat lunak rekrutmen pegawai. Dengan demikian perangkat lunak rekrutmen pegawai yang dihasilkan benar-benar sesuai dengan kebutuhan Polbeng.

\section{REFERENSI}

[1] Firdaus, A dan Maarif, M. S. (2015). Aplikasi Soft System Methodology (SSM) Untuk Perencanaan Terintegrasi Biofuel Dalam sektor pertanian dan sektor energi. Jurnal PASTI . 9 (1). $1-9$

[2] Iswari, M, N, S (2012). Tinjauan Proses Elisitasi Kebutuhan Perangkat Lunak Menggunakan Metode Agile . Jurnal ULTIMATIC. 9 (1). 33 36

[3] Lewenusa, I. (2017). Rekayasa kebutuhan perangkat lunak Pada perusahaan skala kecil dan menengah dengan pendekatan Soft System Methodology (SSM) - studi kasus PT XYZ. Computatio: Journal of Computer Science and Information Systems. 1. 49 - 57

[4] Nugroho, H. (2012). Pendekatan Soft System Methodology Untuk Membangun Sebuah Sistem Informasi Proyek Akhir. Proceedings Konferensi Sistem Informasi. 1441 - 1446

[5] Siahaan, D . (2012). Analisa Kebutuhan Dalam Rekayasa Perangkat Lunak. Jogjakarta: Andi Publisher

[6] Yullyanti, E. (2009). Analisis Proses Rekrutmen dan Seleksi pada Kinerja Pegawai. Jurnal Ilmu Administrasi dan Organisasi. 16 (3). 131 - 139 